\title{
ELEMENTARY SCHOOL
}

\section{The changing face of the chemical world.}

\section{BY J. D. TRYE}

A t the start of the twenty-first century, it was a widely held belief that the remarkable tool underpinning the organization of chemistry was as complete as it could be. Struggles to extend the periodic table into the ' $\mathrm{g}$ block' and beyond had stalled, and researchers had largely abandoned the effort. From our privileged position in history, we, of course, know how wrong they were. Here are some of the key additions to the periodic table that have been made in the intervening years.

\section{POTTERIUM}

Discovered by chance in an all-night session using the ultra-ultra-fast collider, potterium has the atomic number 9.75. Although lighter than many elements in the table, it remains tricky to make. The most consistent method involves a set-up similar to Young's double-slit experiment. A beam of particles is fired precisely at the mid-point between two slits in a metal box, and trace amounts of potterium appear on the other side.

\section{REDTAPIUM}

The first half of the twenty-first century was characterized by a rapid collapse in international relations and an increase in isolationist policies. It soon became clear that there was something going on beyond smallminded avarice and a fear of the unknown. Redtapium was the first of the group now called the entropic elements to be discovered. Collectively, this group brings to bear forces that promote the second law of thermodynamics. Redtapium is relatively common, exerting its effects at both local and macro levels by making anything anyone wants to do just that little bit harder than it needs to be.

\section{MUISEAC}

One of the most exciting development in the burgeoning field of elemental chemistry was what is now euphemistically called mirror physics but should be more properly described as antimatter science. By the end of the twentieth century, significant progress had been made in understanding antimatter, and the generation of short-lived anti-particles. But it took another 200 years before a team of researchers trying to make a really good instant coffee accidentally created a tabletop black hole that allowed them to make mirror images of not just particles but also the elements themselves. As might be expected, the properties of the anti-elements are effectively

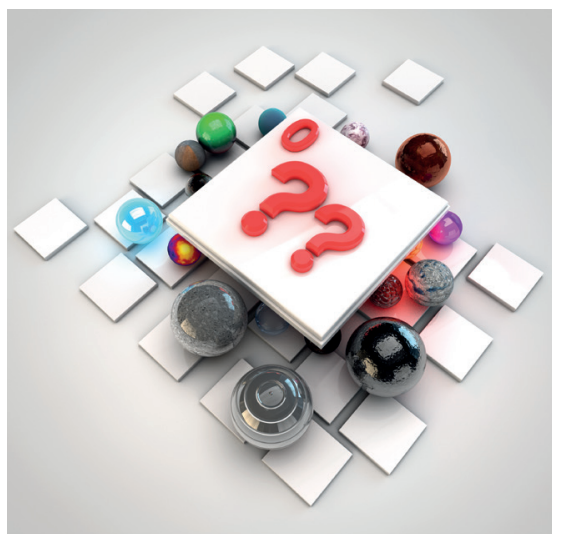

the opposite of their matter counterparts. Only a few have been made since negyxo escaped from a reaction vessel and sucked all of the life out of a part of Birmingham (although some archly say they can't tell the difference), but the extraordinarily stable liquid metal muiseac is now used as fuel to power antimatter drives across the Galaxy.

\section{UNDEADIUM}

If the family of elements known colloquially as the supernaturals had a leader, then undeadium would be it. Reasonable levels of it have been found in all of the creatures now described as living a hyper-alternate lifestyle. Admittedly, it is most often seen in terms of its decay products, such as ghoolium and zombium (where decay is the operative word). Undeadium can only be worked with at night and is usually restricted to labs that have a 5-point-star biosafety rating.

\section{UMUMIUM}

The 'hesitant' element, umumium will react with many substances but only after it has got to know them well and is in comfortable and relaxed surroundings. However, there remains a high activation energy requirement, as simply getting umumium into a situation where it will even approach another element is nigh on impossible.

\section{LAUNDRARIUM}

Another of the entropic elements, laundrarium is known not only for its high reactivity but also its highly selective capabilities. In dark, confined spaces, laundrarium will spontaneously react with small

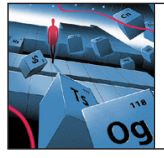

agglomerations of matter, usually shaped like a sock, immediately eliminating them from the environment. Some researchers have suggested the reaction is so thermodynamic that the substrate is catapulted into a parallel universe, others assert that the substrate is wholly consumed by the reaction, breaking down into subatomic particles that simply dissipate. Either way, no post-reaction socklike substrates have ever been recovered.

\section{ZENOBIUM}

Also known as unobtanium, zenobium is the most elusive of the new elements in the periodic table and lingers just out of reach. Many teams have claimed to have isolated it only to find that when they looked more closely it wasn't where they thought they had left it.

\section{HIVIZIBILIUM}

Closely related to blinginium, hivizibilium is a meta-element that affects the nature of electromagnetic radiation perceived to be emanating from an object. It was first isolated from the iridescent teeth of z-list TV celebrities, but has subsequently been identified as a key component of fake tans, overturning in the process the controversial hypothesis on the existence of orangiston, which had been proposed to be released when someone signs up for a reality TV show.

\section{TRANSUBSTANTIUM}

One of the newly discovered transition elements, transubstantium cannot currently be isolated in its pure form as it immediately acts upon its surroundings to convert them into something else. Discovered when a glass of water inexplicably became a thick red liquid, transubstantium has now been seen in many reactions, including the conversion of a pleasant meal for two with wine into an unexpectedly large bill.

\section{ARRETIUM}

A gaseous element, the existence of which is currently only inferred. It is thought to be generated in urban environments, especially in train stations and pedestrian walkways. Exceptionally high levels are believed to accumulate in doorways and at the top of staircases. Although most of its properties remain to be discovered, it is known to have a direct effect on the central nervous system of humans, temporarily paralysing their core motor functions at unexpected moments.

J. D. Trye works in an office by day and worries about the future by night. 